\title{
Should surgical drainage after lateral transperitoneal laparoscopic adrenalectomy be routine? -A retrospective comparative study
}

\author{
Shuaishuai Chai ${ }^{1 \#}$, Qiufeng Pan ${ }^{2 \#}$, Chaoqi Liang ${ }^{1 \#}$, Hao Zhang ${ }^{1}$, Xingyuan Xiao ${ }^{1},{\text { Bing } \text { Li }^{1} \wedge}^{1}$ \\ ${ }^{1}$ Department of Urology, Union Hospital, Tongji Medical College, Huazhong University of Science and Technology, Wuhan, China; ${ }^{2}$ Department of \\ Urology, The First Affiliated Hospital of Nanchang University, Nanchang, China \\ Contributions: (I) Conception and design: B Li, X Xiao, S Chai; (II) Administrative support: B Li, X Xiao; (III) Provision of study materials or \\ patients: S Chai, Q Pan; (IV) Collection and assembly of data: S Chai, Q Pan, B Li; (V) Data analysis and interpretation: S Chai, Q Pan, C Liang; \\ (VI) Manuscript writing: All authors; (VII) Final approval of manuscript: All authors. \\ "These authors contributed equally to this work. \\ Correspondence to: Bing Li, MD, PhD; Xingyuan Xiao, MD, PhD. Department of Urology, Union Hospital, Tongji Medical College, Huazhong \\ University of Science and Technology, Wuhan 430022, China. Email: bingli@hust.edu.cn; xiaoxy@hust.edu.cn.
}

\begin{abstract}
Background: Whether to use surgical drains after abdominal surgery or not has received much attention since a hundred years ago. Nowadays, lateral transperitoneal laparoscopic adrenalectomy (LTLA) is a widely used technique to treat adrenal tumors worldwide. However, the placement of drains after LTLA remains controversial.

Methods: Data of 150 patients, who underwent LTLA between October 2014 and September 2020 by the same lead surgeon, were collected, including demographic, pathology, preoperative, operative variables and postoperative complications. The patients were divided into two groups, with and without drainage. The postoperative recovery of the two groups was compared.

Results: Among 150 patients (65 men and 85 women, median age 48 years, median BMI 23.53), 89 patients had no drainage and 61 patients had drainage after surgery. Variables of the two groups were analyzed. Placement of drains correlated with long operative time $(\mathrm{P}<0.01)$. Patients with drain had longer hospital stays $(\mathrm{P}<0.001)$ and a higher incidence of postoperative complications $(\mathrm{P}=0.022)$. Other factors, including tumor size $(\mathrm{P}=0.61)$, tumor location $(\mathrm{P}=0.387)$, ASA score $(\mathrm{P}=0.687)$, pathology $(\mathrm{P}=0.55)$, VAS pain score $(\mathrm{P}=0.41)$, intraoperative blood loss $(\mathrm{P}=0.11)$, were not found to be significantly associated with drain placement. There was no conversion to open surgery in both groups. Moreover, no mortality was observed in either group.
\end{abstract}

Conclusions: This study revealed that it is feasible and safe not to leave a drain in selective and uncomplicated patients and that surgical drainage should not be routine after LTLA.

Keywords: Lateral transperitoneal laparoscopic adrenalectomy (LTLA); drain; adrenal tumor; postoperative recovery

Submitted Nov 14, 2020. Accepted for publication May 07, 2021.

doi: $10.21037 /$ gs-20-829

View this article at: https://dx.doi.org/10.21037/gs-20-829

\section{Introduction}

Whether to use surgical drains after abdominal surgery or not has received much attention since 100 years ago
(1), and evolving into a permanently controversy (2). Nowadays, despite considerable progress in minimally invasive technique, the use of drains remains unchanged for prophylactic purpose and even become dogmatic. Since

\footnotetext{
$\wedge$ ORCID: 0000-0002-7041-6701.
} 
1992, lateral transperitoneal laparoscopic adrenalectomy (LTLA) has been widely used in the treatment of benign and malignant adrenal tumors (3-8), As with other intraabdominal surgeries, placement of drains on the operative field is a common practice in order to realize early postoperative bleeding and drain remnant intraperitoneal liquids. However, whether it will benefit or not still turns out to be ambiguous. Evidences based on laparoscopic cholecystectomy (LC) and splenectomy showed that operative field drainage may be responsible for increased complications $(9,10)$. Nevertheless, little attention has been paid to laparoscopic adrenalectomy. In this study, we retrospectively compare patients undergoing LTLA with and without surgical drainage, and investigate whether it is indispensable. We present the following article in accordance with the STROBE reporting checklist (available at https://dx.doi.org/10.21037/gs-20-829).

\section{Methods}

\section{Patients}

The study was conducted in accordance with the Declaration of Helsinki (as revised in 2013). The study was approved by the Ethics Committee of the Union Hospital, Tongji Medical College, Huazhong University of Science and Technology (No. 20210231) and individual consent for this retrospective analysis was waived. Between October 2014 and September 2020, all patients suspected of adrenal disease underwent imaging studies (ultrasound, computed tomography, magnetic resonance imaging and positron emission computed tomography if necessary); moreover, to ascertain whether the tumor possess hormonal activity or not, a complete preoperative endocrine evaluation and routine comprehensive laboratory examination was conducted. For patients suspected of pheochromocytoma, I-131 metaiodobenzylguanidine scintigraphy was also performed. The criteria of patient selection for this trial were as follows: (I) adrenal gland tumors secreting excessive hormone verified by laboratory test; (II) hormonally inactive tumors but its size exceeds $4 \mathrm{~cm}$ or its laboratory enlargement in a year exceeds $1 \mathrm{~cm}$ during observation; (III) suspicious of malignant transformation through imageological examination. Meanwhile, the exclusion criteria was based on the following: patients with a history of previous abdominal surgery who had severe abdominal adhesions, which required conversion to open surgery; patients who presented with iatrogenic ambient organs injury intraoperatively during LTLA, which required additional management or even conversion to open surgery; patients who needed conversion to open surgery for other reasons; patients who had undergone single incision laparoscopic surgery or operation on other organ simultaneously; patients who presented with any features of active bacterial infection before surgery; patients who have taken drugs that affect blood coagulation function (except low molecular weight heparin at preventive doses) or have abnormal blood coagulation function before surgery. We divided patients into group A (no drain) and group B (drain) and reviewed their clinical data. Characteristics of patients were evaluated include sex, age, body mass index (BMI), American Society of Anesthesiologists (ASA) class (11), tumor size, tumor location and pathological diagnosis. The surgical outcomes (operative time, intraoperative blood loss, postoperative nausea and vomiting (PONV), postoperative pain score and postoperative hospital stay) were also analyzed. Postoperative complications were analyzed according to the Clavien-Dindo classification (12).

\section{Surgical technique}

All operations were performed in Department of Urology, Union Hospital, Wuhan, China by the same surgeon through transperitoneal lateral approach. All patients received preoperative prophylaxis against infection and venous thrombosis according to hospital protocol. After general anesthesia, a Foley catheter was usually inserted to decompress the bladder and generally removed as soon as the patient could get out of bed and move. All operations were done by the same surgeon. A LTLA was used in all patients. The detailed operation process can refer to the following literature (8,13-17). Briefly, patients were positioned lateral decubitus (for the right adrenal, $70^{\circ}$ left lateral decubitus; for the left adrenal, $70^{\circ}$ right lateral decubitus). Four trocars were used for right LTLA and three for left LTLA (sometimes a fourth trocar was needed to help retract the spleen in the left). The main adrenal vein was double-clipped and divided; the accessory veins and arteries were cauterized with sealing technology and sectioned. The adrenal gland with the tumor and periadrenal fat was completely excised. As shown in Figures 1 and 2. At the end of surgery, the lead surgeon decided whether to leave a drain or not was based on the specific conditions during the operation, such as intraoperative blood loss and operation time, and the size of the wound in the operation area. If a drain was placed 

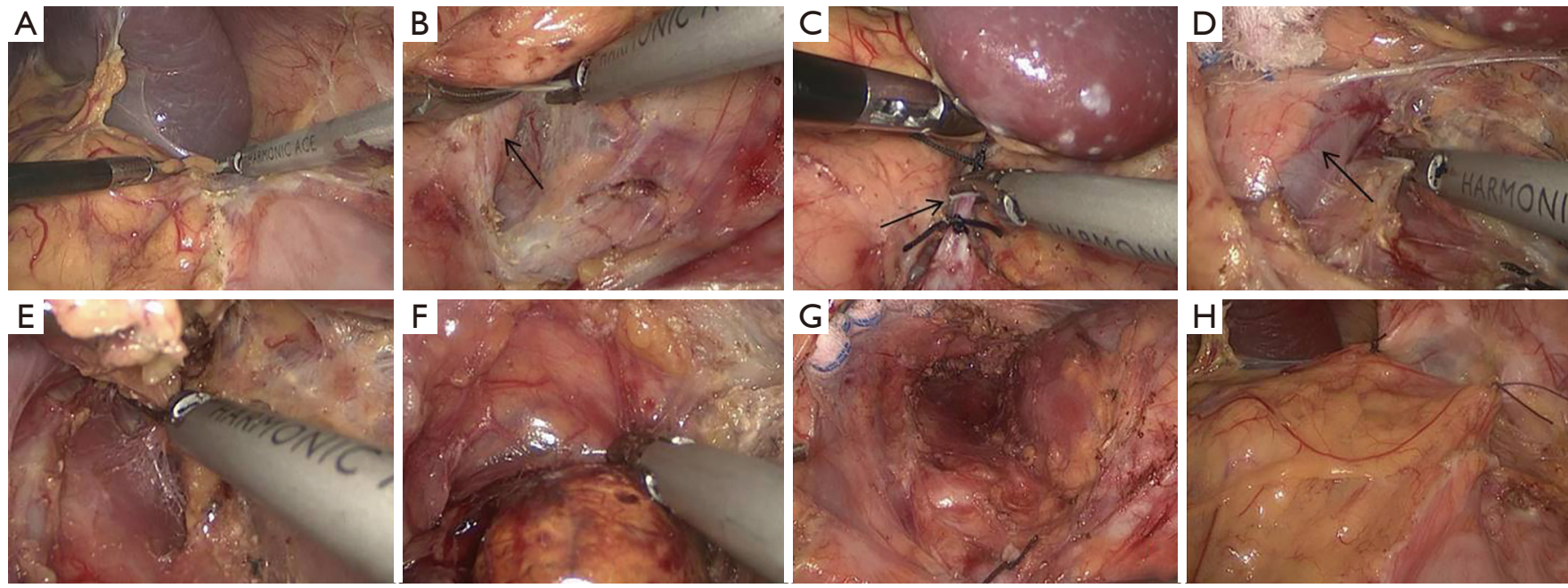

Figure 1 Left adrenalectomy (A) Dissection of splenocolic and lienorenal ligament to expose surgical field; (B) the plane between Gerota's fascia and the tail of pancreas (black arrow) should be developed clearly; (C) isolation and dissection of left adrenal vein (black arrow); (D) mobilization of medial part of gland carefully to avoid injury to spleen vessel (black arrow); (E) mobilization of adrenal posterior and lateral attachments; (F) dissection of upper vessels feeding the gland with the harmonic scalpel; $(\mathrm{G})$ the operative field after removal of specimen; (H) restoration of anatomy structure without drainage.
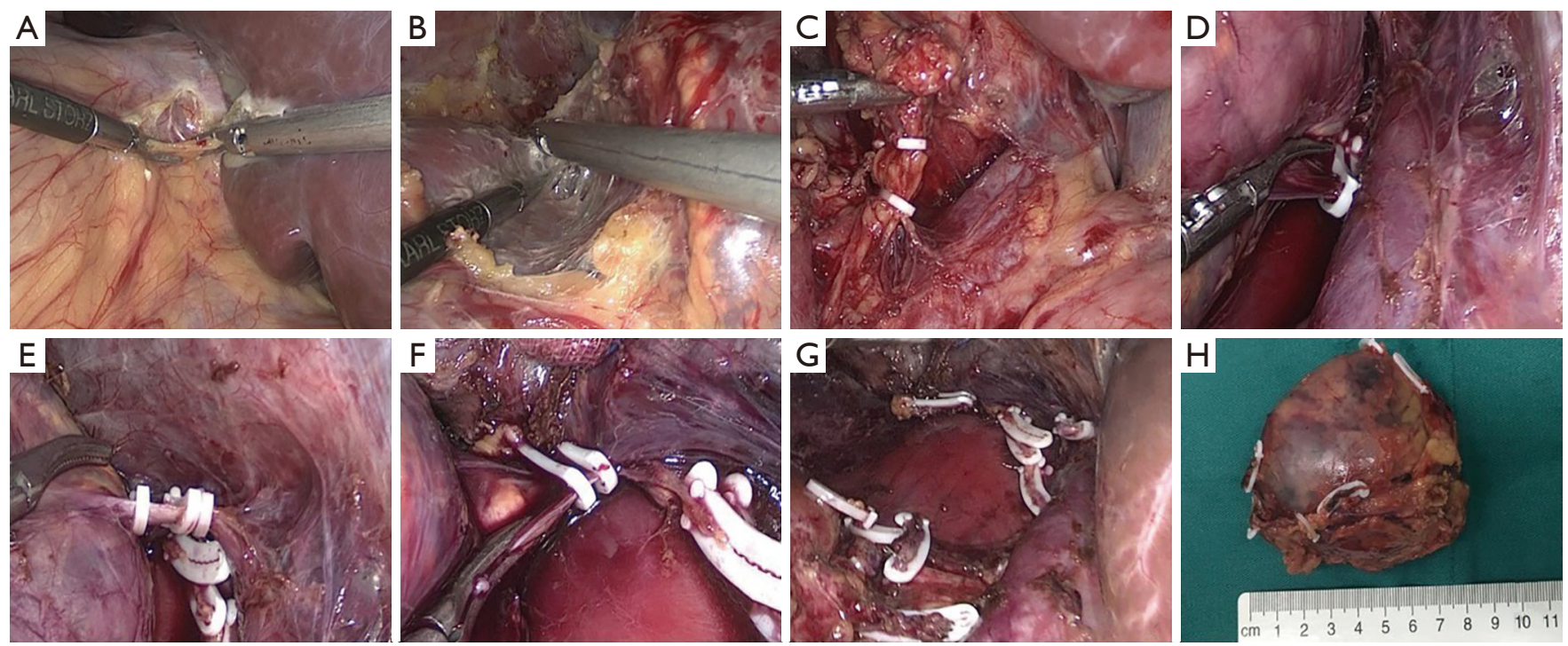

Figure 2 Right adrenalectomy (A) Incision of hepatocolic and liver triangular ligaments to facilitate cephalad retraction of liver; (B) the junction between the upper pole of kidney and the adrenal gland was incised to help dealing with the inferior vascular pedicles; (C) the inferior arterial vessels were controlled with hemoclips; (D) cautious dissection along the lateral vena cava allowed dissection of middle arterial feeding vessels; (E) exposure and dissection of the right adrenal vein arising the vena cava; $(\mathrm{F})$ inferior phrenic vessels can be easily identified and ligated with hemoclips; $(\mathrm{G})$ the operative field; $(\mathrm{H})$ approximately $8 \mathrm{~cm}$ tumor. 
at the organ removal site, this patient was enrolled in "drain" group, if not draining, this patient was included as "no drain" group. To ensure a successful laparoscopic adrenalectomy with minimal morbidity, complete knowledge of surgical anatomy, cautious dissection techniques and hemostasis are paramount.

\section{Postoperative management}

All the patients were given standard and meticulous care postoperatively include established enhanced recovery. All patients were mobilized early and were encouraged to ambulate as soon as possible (all were sitting up and walking within a few hours after surgery). Oral ingestion was introduced within 8-12 h after surgery on the condition that there was no nausea and vomiting. Postoperative pain was evaluated using visual analogue scale (VAS) (18) from 0 to 10 , which was completed $24 \mathrm{~h}$ after surgery with regard to either abdominal or shoulder pain. PONV was assessed at $8 \mathrm{~h}$ after operation by asking patients about their symptoms, and if the patient had nausea or vomiting, the PONV was regarded as positive. In the "drain" group, drained fluid volume was recorded every day and drainage tube was not removed until drained fluid was less than $10 \mathrm{~mL}$ per day; while in the "no drain" group, for patients with abnormal abdominal physical examination or abdominal pain and discomfort, the operative field ultrasonography was performed routinely instead on the first postoperative day to detect possible fluid collection and the volume was calculated if necessary. All patients, except those who required conversion to open surgery or developed complications, were discharged early. Postoperative complications were also recorded within 4 weeks after discharge.

\section{Statistical analysis}

All the analyses were performed using SPSS version 23.0 software (SPSS, Inc., Chicago, IL, USA). The ShapiroWilk test was applied to ascertain normal distribution of parameters. Categorical variables are expressed as frequencies and percentages. And categorical data were compared using the chi-square test or Fisher's exact test. Data from continuous variables were expressed as mean \pm the standard deviation or medians and ranges. Differences in the normally distributed continuous data were compared using the independent samples $t$-test and the Mann-Whitney $U$ test for non-normally distributed continuous variables, respectively.

Univariate and multivariate analysis (logistic regression) tables were used to assess risk factors independent of drain. Associations between postoperative hospital stay and preoperative, intraoperative, pathology variables, postoperative VAS score and drain (or no drain) were tested using linear regression. Variables with $\mathrm{P} \leq 0.10$ in univariate logistic or univariate linear regression were included in the multivariate logistic or multivariate linear regression models to generate adjusted odds ratios (OR) or adjusted means. In logistic regression, ORs, 95\% confidence intervals (CI), and associated $\mathrm{P}$ values are reported. In linear regression, $\mathrm{B}$, standard error (SE), 95\% confidence intervals (CI) for B, $\beta$, and associated $\mathrm{P}$ values are reported. For all tests, $\mathrm{P}$ value $<0.05$ was considered statistically significant.

\section{Results}

As a result, 150 patients in total met our criteria and were submitted to our study. The operative method performed for all patients was LTLA. Among the study of 150 patients, 89 patients were "no drain" group and 61 patients were "drain" group. The mean age was 47.68 years (range, 1568 years), the mean BMI was 23.53 (range, 17-34), the mean size of removed tumor was $2.66 \mathrm{~cm}$ (range, 0.6-8 cm), there was no significant difference between "drain" and "no drain" group $(\mathrm{P}>0.05)$. There also was no significant difference between "drain" and "no drain" group in sex $(\mathrm{P}=0.389)$, tumor location $(\mathrm{P}=0.387)$ ASA score $(\mathrm{P}=0.687)$ and pathology $(\mathrm{P}=0.55)$. The demographic characteristics of the two groups are presented in Table 1.

Among 150 patients, the mean intraoperative blood loss was $41.58 \mathrm{~mL}$ (range, 9-160 mL) including "no drain" 38.79 $\mathrm{mL}$ and "drain" $45.66 \mathrm{~mL}$ respectively, and there was no significant difference between two groups $(\mathrm{P}>0.05)$. The mean operative time was $58.48 \mathrm{~min}$ (range, 25-135 min) including "no drain" $50.70 \mathrm{~min}$ and "drain" $69.84 \mathrm{~min}$ respectively and the mean operative time was shorter in the "no drain" group $(\mathrm{P}<0.01)$. The mean VAS pain score was 1.73 (range, 1-4) and there also was no significant difference between two groups $(\mathrm{P}>0.05)$. While postoperative hospital stay was 3.07 days (range, 1-11 days), there was significant difference between two groups $(\mathrm{P}<0.05)$. The length of postoperative hospital stay in the "drain" group was markedly longer than patients in the "no drain" group $(\mathrm{P}<0.001)$. No patients were converted to open surgery or reoperation (Table 2). Total complications occurred more frequently in "drain" group than in "no drain" group (12 vs. 6, $\mathrm{P}=0.022)$, but most were Clavien-Dindo grade 1 (Table 3).

Table 4 demonstrates the results of the univariate and multivariable logistic regression analyses of risk factors 
Table 1 Demographic and pathological characteristics

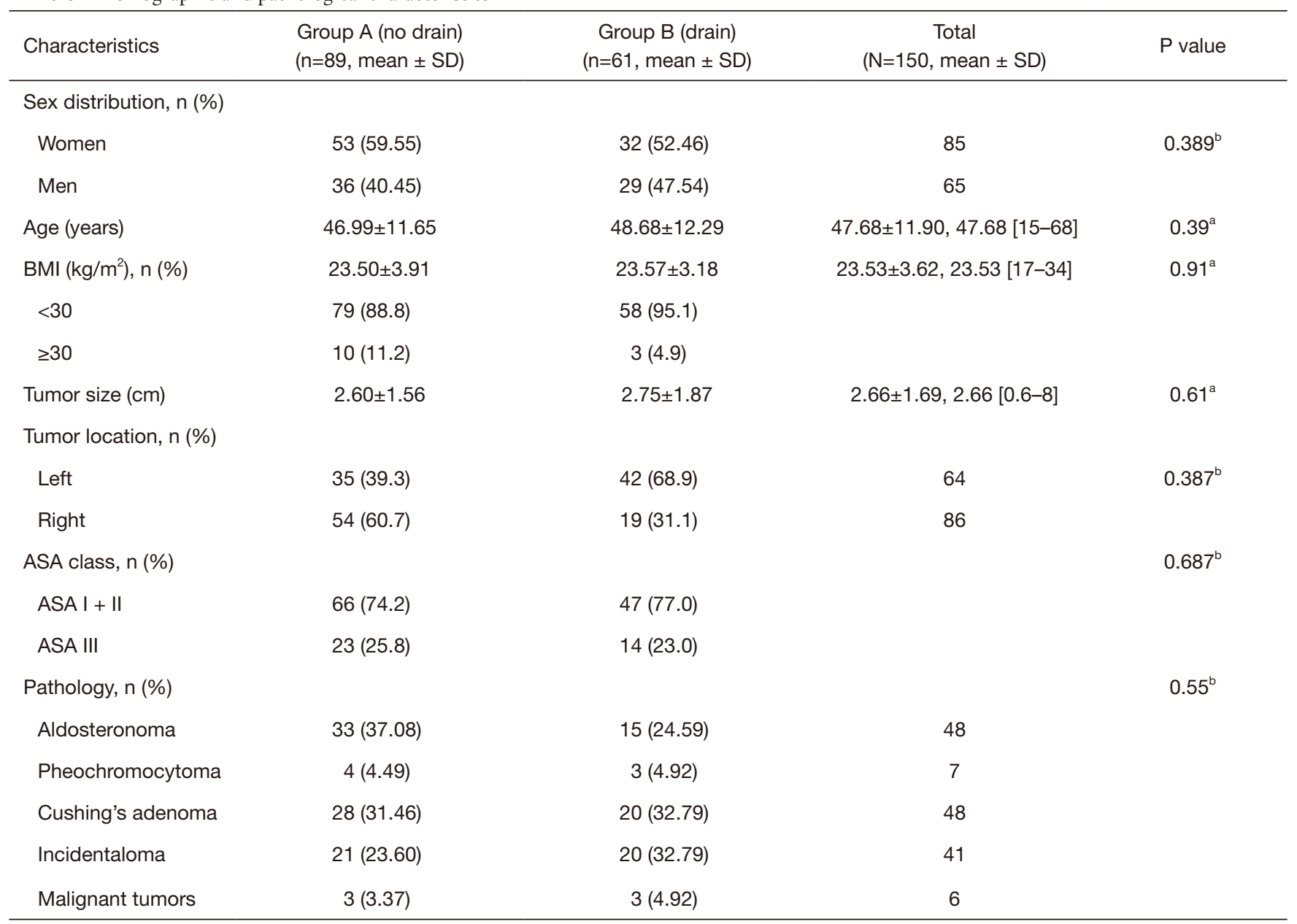

${ }^{\mathrm{a}}$, independent samples $t$-test; ${ }^{\mathrm{b}}$, chi-square test.

Table 2 Surgical outcomes

\begin{tabular}{|c|c|c|c|c|}
\hline Characteristics & $\begin{array}{l}\text { Group A (no drain) } \\
(\text { mean } \pm \mathrm{SD})(\mathrm{N}=89)\end{array}$ & $\begin{array}{c}\text { Group B (drain) } \\
(\text { mean } \pm \mathrm{SD})(\mathrm{N}=61)\end{array}$ & $\begin{array}{c}\text { Total } \\
(\text { mean } \pm \mathrm{SD})(\mathrm{N}=150)\end{array}$ & $P$ value \\
\hline Postoperative hospital stay (days) & $2.57 \pm 0.72$ & $3.80 \pm 1.73$ & $3.07 \pm 1.37,3.07[1-11]$ & $<0.001^{\mathrm{a}}$ \\
\hline Operative time (min) & $50.70 \pm 15.46$ & $69.84 \pm 21.37$ & $58.48 \pm 20.35,58.48[25-135]$ & $<0.01^{a}$ \\
\hline Intraoperative blood loss (mL) & $38.79 \pm 25.07$ & $45.66 \pm 26.61$ & $41.58 \pm 21.84,35.11[9-160]$ & $0.11^{\mathrm{a}}$ \\
\hline Reoperation & 0 & 0 & - & - \\
\hline
\end{tabular}

${ }^{\mathrm{a}}$, independent samples $t$-test. 
Table 3 Postoperative complications

\begin{tabular}{lccc}
\hline Complications & Group A (no drain) (N=89) & Group B (drain) (N=61) & P value \\
\hline SUM & 6 & 12 & $0.022^{\mathrm{b}}$ \\
Clavien-Dindo grade 1, n (\%) & 6 & $4(6.56)$ & $6(9.84)$ \\
Wound hematoma or infections & $1(1.12)$ & 2 & $0.355^{\mathrm{b}}$ \\
PONV & $5(5.62)$ & $2(3.28)$ & $0.164^{\mathrm{b}}$ \\
Clavien-Dindo grade 2, n (\%) & 0 & \\
Postoperative infection & 0 & 0 \\
Not wound infections & 0 & 0 \\
Clavien-Dindo grade 3 & 0 & 0 \\
Clavien-Dindo grade 4 & 0 & \\
Clavien-Dindo grade 5 & 0 & \\
\hline
\end{tabular}

b, chi-square test. SUM, sum total.

Table 4 Multivariable logistic regression for placement of drain

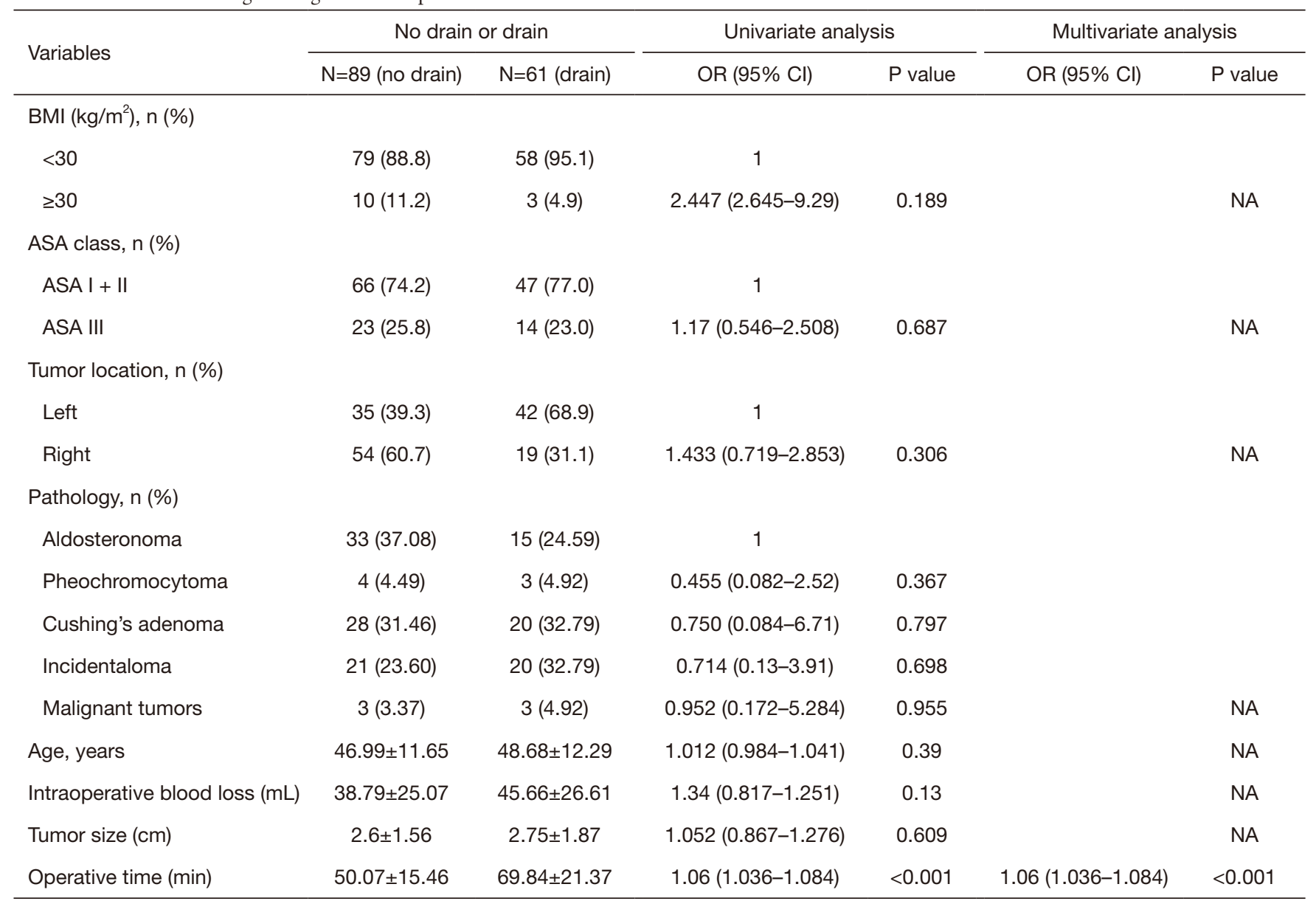

BMI, body mass index; ASA, American Society of Anesthesiologist Physical Status Classification System; OR, odds ratio; Cl, confidence interval. 
Table 5 Results of the univariate and multivariate linear regression model for Postoperative hospital stay

\begin{tabular}{|c|c|c|c|c|c|c|}
\hline Variables & \multicolumn{2}{|c|}{ Unstandardized coefficients } & \multicolumn{2}{|c|}{$95 \% \mathrm{Cl}$ for $\mathrm{B}$} & \multicolumn{2}{|c|}{ Standardized } \\
\hline \multicolumn{7}{|c|}{ Univariate linear regression model } \\
\hline Age & 0.004 & 0.009 & -0.013 & 0.015 & 0.036 & 0.662 \\
\hline $\mathrm{BMI}\left(<30 \mathrm{~kg} / \mathrm{m}^{2}\right)$ & -0.586 & 0.396 & -1.369 & 0.198 & -0.121 & 0.142 \\
\hline Cushing's adenoma & -0.438 & 0.278 & -0.987 & 0.112 & -0.149 & 0.118 \\
\hline Incidentaloma & -0.274 & 0.29 & -0.847 & 0.298 & -0.089 & 0.345 \\
\hline Malignant tumors & 0.75 & 0.59 & -0.416 & 1.916 & 0.108 & 0.206 \\
\hline Tumor size & 0.053 & 0.067 & -0.079 & 0.185 & 0.065 & 0.431 \\
\hline ASA (III) & 0.003 & 0.371 & -0.436 & 0.731 & 0.011 & 0.994 \\
\hline VAS & 0.526 & 0.146 & 0.238 & 0.814 & 0.284 & 0.000 \\
\hline Operative time & 0.009 & 0.005 & -0.001 & 0.02 & 0.14 & 0.087 \\
\hline Intraoperative blood loss & 0.018 & 0.004 & 0.01 & 0.026 & 0.353 & 0.000 \\
\hline Drain & 1.23 & 0.205 & 0.825 & 1.636 & 0.442 & 0.000 \\
\hline \multicolumn{7}{|c|}{ Multivariate linear regression model } \\
\hline VAS & 0.440 & 0.129 & 0.185 & 0.695 & 0.238 & 0.001 \\
\hline Operative time & -0.007 & 0.005 & -0.018 & 0.003 & -0.104 & 0.187 \\
\hline
\end{tabular}

BMI, body mass index; ASA, American Society of Anesthesiologist Physical Status Classification System; SE, standard error; Cl, confidence interval.

independent of drainage. The placement of the drainage was only related to the operation time (OR 1.06, 95\% CI: 1.036-1.084, $\mathrm{P}<0.001)$. The results of the univariate and multivariate linear regression analysis of factors associated with postoperative hospital stay are shown in Table 5. It could be found by univariate linear regression analysis that VAS, operative time and placement of drain could all lead to longer hospitalization days $(\mathrm{P}<0.05)$. And multivariate analysis showed that placement of drain was the factor most responsible for prolongation of hospitalization days compared to other factors $(\mathrm{P}<0.001)$.

\section{Discussion}

Since the first laparoscopic adrenalectomy was introduced in
1992 by Gagner et al. $(8,19)$, this technique was developed and popularized rapidly due to its better cosmetic effect, lower complication rate, reduced postoperative analgesia assumption and early discharge; therefore, it becomes a gold standard treatment for benign or malignant adrenal tumors $(6,7,20,21)$. However, there is still limited evidence proving the value of surgical drainage after LTLA. More importantly, drains themselves may increase postoperative morbidity (22). This leads to discordance among surgeons in minimally invasive era.

Surgical drains are used mostly for therapeutic purposes for drainage of intra-abdominal abscess caused by bowel perforation, pancreatic fistula (1). Moreover, we believe it is necessary to insert a drain when intraoperative complications occur such as injury to inferior vena cava or 
the tail of pancreas to detect early bleeding or fistula (23). In our study, no patients in both groups presented with above serious complications. Nowadays, however, drains are frequently used for prophylactic purposes and served as mentally comfort. They expected that placement of drain will help identify early postoperative bleeding and prevent intra-abdominal abscess formation. Nevertheless, no study available demonstrates the effectiveness of prophylactic surgical drainage. However, in our retrospective comparative study total complications occurred more frequently in "drain" group than in "no drain" group (12 vs. 6, $\mathrm{P}=0.022$ ), although most were Clavien-Dindo grade 1 .

At present, intra or post-operative complications after laparoscopic adrenalectomy are rare, especially uncomplicated cases (24). Studies have shown complication rates of laparoscopic adrenalectomy ranging from $6.5 \%$ to $15 \%(5,15,25-28)$. In our retrospective study, total complications were $12 \%$ (18/150), mainly ClavienDindo grade 1 minor complications, of which $19.67 \%$ $(12 / 61)$ and $6.74 \%(6 / 89)$ in the group with and without drains, respectively. This indicates that the clinical effect of drains has decreased and is more likely to bring about postoperative discomfort. Moreover, in an experimental study, Agrama et al. (29) showed that if a drain is inserted under the circumstances of no fluid in peritoneal cavity, the drain will be surrounded and occluded by omentum. Therefore, the absence of blood from the drain, in some cases, cannot indicate a nonexistence of bleeding. Even if significant postoperative bleeding occurs, ultrasound examinations used in our study and clinical symptoms can also identify successfully. Beyond that, Georgiou et al. (30) showed that after LC, drains increase occurrence of fluid collections in the operative region. Consequently, the routine use of drain is questionable.

Many patients complain of pain and PONV after laparoscopical operation (31). The pain may occur in the abdomen, back or shoulder. The origin of postoperative pain is multifactorial, with pain arising from pneumoperitoneum, incision sites and lesion removed region. Nausea and vomiting may be induced by the pneumoperitoneum. Lots of surgeons still hold that the drain can help reduce pain and PONV by discharging residual gas. However, many studies concerning LC reported that the drain has no effect on reduced pain and PONV $(23,32)$. In our study, there was no statistical difference with regard to PONV or VAS pain score. Nevertheless, a limitation in the present study should not be ignored. We only evaluated PONV or pain at one point after surgery; therefore, it cannot represent the whole recovery process.
Besides, drainage seems to increase the incidence of infectious complications (10). In our study, postoperative infection is more likely to occur in patients with drainage tubes $(1 / 89,6 / 61, \mathrm{P}=0.037)$. It indicates that the drain left in the operative field as it is not only a passage to remove the contents from the abdominal cavity, but also a potential source of infection (33). Therefore, attention should also be paid to the infectious complications related to the inflammatory response caused by the drainage tube. In 1962, Myers described a "drain fever syndrome" which is basically fever with no accompanying symptoms of infection in patients with post-operational drainage, and the syndrome disappears after removing the drain (34).

With respect to postoperative hospital stay, studies indicated that postoperative drainage also prolongs $(24,35,36)$. Our results were in line with them. However, many factors such as personal physical condition, the recovery process have an effect on postoperative hospital stay. Therefore, associations between postoperative hospital stay and preoperative, intraoperative, pathology variables, postoperative VAS score and drain (or no drain) were tested using linear regression. It could be found by univariate linear regression analysis that higher VAS score, more intraoperative blood loss and placement of drain could all lead to longer hospitalization days $(\mathrm{P}<0.05)$. And multivariate analysis showed that placement of drain was the factor most responsible for prolongation of hospitalization days compared to other factors $(\mathrm{P}<0.001)$. So the argument that drainage can help shorten postoperative hospital stay is untenable. And no drain makes outpatient laparoscopic adrenalectomy possible. Actually, some patients in our "no drain" group meet the outpatient surgery criteria (37). In the future, we believe we can also perform laparoscopic adrenalectomy as an outpatient procedure in selected patients.

However, in our retrospective study, despite our including all patients with no drain and making inclusion and exclusion criteria clear, several limitations to this study need to be considered. Firstly, this was a single-center study including only the same surgeon, so caution is warranted in extrapolating the results to other scenarios. Secondly, the selection of patient types is not comprehensive enough, and the number of patients with each pathological type is needed more. Therefore, in the near future, a well-designed prospective study is requisite to reduce bias.

\section{Conclusions}

In summary, LTLA surgery has proven safe for adrenal 
tumors. And this study revealed that it is feasible and safe not to leave a drain in selective and uncomplicated patients and that surgical drainage should not be routine after LTLA.

\section{Acknowledgments}

We acknowledge Clare Mao for English language editing. Funding: This work was supported by the National Natural Science Foundation of China (grant number 81671216, 81371379).

\section{Footnote}

Reporting Checklist: The authors have completed the STROBE reporting checklist. Available at https://dx.doi. org/10.21037/gs-20-829

Data Sharing Statement: Available at https://dx.doi. org/10.21037/gs-20-829

Peer Review File: Available at https://dx.doi.org/10.21037/ gs-20-829

Conflicts of Interest: All authors have completed the ICMJE uniform disclosure form (available at https://dx.doi. org/10.21037/gs-20-829). The authors have no conflicts of interest to declare.

Ethical Statement: The authors are accountable for all aspects of the work in ensuring that questions related to the accuracy or integrity of any part of the work are appropriately investigated and resolved. The study was conducted in accordance with the Declaration of Helsinki (as revised in 2013). The study was approved by the Ethics Committee of the Union Hospital, Tongji Medical College, Huazhong University of Science and Technology (No. 20210231) and individual consent for this retrospective analysis was waived.

Open Access Statement: This is an Open Access article distributed in accordance with the Creative Commons Attribution-NonCommercial-NoDerivs 4.0 International License (CC BY-NC-ND 4.0), which permits the noncommercial replication and distribution of the article with the strict proviso that no changes or edits are made and the original work is properly cited (including links to both the formal publication through the relevant DOI and the license). See: https://creativecommons.org/licenses/by-nc$\mathrm{nd} / 4.0 /$.

\section{References}

1. Duthie HL. Drainage of the abdomen. N Engl J Med 1972;287:1081-3.

2. Schein $M$. To drain or not to drain? The role of drainage in the contaminated and infected abdomen: an international and personal perspective. World J Surg 2008;32:312-21.

3. Brix D, Allolio B, Fenske W, et al. Laparoscopic versus open adrenalectomy for adrenocortical carcinoma: surgical and oncologic outcome in 152 patients. Eur Urol 2010;58:609-15.

4. Gagner M, Pomp A, Heniford BT, et al. Laparoscopic adrenalectomy: lessons learned from 100 consecutive procedures. Ann Surg 1997;226:238-46; discussion 246-7.

5. Chen Y, Scholten A, Chomsky-Higgins K, et al. Risk Factors Associated With Perioperative Complications and Prolonged Length of Stay After Laparoscopic Adrenalectomy. JAMA Surg 2018;153:1036-41.

6. Patel N, Egan RJ, Carter BR, et al. Outcomes of surgery for benign and malignant adrenal disease from the British Association of Endocrine and Thyroid Surgeons' national registry. Br J Surg 2019;106:1495-503.

7. Rodríguez-Hermosa JI, Delisau O, Planellas-Giné $\mathrm{P}$, et al. Factors associated with prolonged hospital stay after laparoscopic adrenalectomy. Updates Surg 2021;73:693-702.

8. Raffaelli M, De Crea C, Bellantone R. Laparoscopic adrenalectomy. Gland Surg 2019;8: S41-S52.

9. Gurusamy KS, Samraj K. Routine abdominal drainage for uncomplicated open cholecystectomy. Cochrane Database Syst Rev 2007;(2):CD006003.

10. Cerise EJ, Pierce WA, Diamond DL. Abdominal drains: their role as a source of infection following splenectomy. Ann Surg 1970;171:764-9.

11. Doyle DJ, Garmon EH. American Society of Anesthesiologists Classification (ASA Class). In StatPearls. Treasure Island (FL), 2018.

12. Dindo D, Demartines N, Clavien PA. Classification of surgical complications: a new proposal with evaluation in a cohort of 6336 patients and results of a survey. Ann Surg 2004;240:205-13.

13. Rodríguez Hermosa JI, Roig García J, Font Pascual JA, et al. Evolution of laparoscopic adrenal surgery in a general surgery department. Cir Esp 2008;83:205-10. 
14. Rodríguez-Hermosa JI, Roig-García J, GironèsVilà J, et al. Laparoscopic adrenalectomy for a large pheochromocytoma in a morbidly obese patient. Obes Surg 2010;20:1195-7.

15. Rodríguez-Hermosa JI, Ranea A, Delisau O, et al. Threedimensional (3D) system versus two-dimensional (2D) system for laparoscopic resection of adrenal tumors: a casecontrol study. Langenbecks Arch Surg 2020;405:1163-73.

16. Shichman SJ, Herndon CD, Sosa RE, et al. Lateral transperitoneal laparoscopic adrenalectomy. World J Urol 1999; 17:48-53.

17. Bickenbach KA, Strong VE. Laparoscopic transabdominal lateral adrenalectomy. J Surg Oncol 2012;106:611-8.

18. Huskisson EC. Measurement of pain. Lancet 1974;2:1127-31.

19. Gagner M, Lacroix A, Bolte E. Laparoscopic adrenalectomy in Cushing's syndrome and pheochromocytoma. N Engl J Med 1992;327:1033.

20. Smith CD, Weber CJ, Amerson JR. Laparoscopic adrenalectomy: new gold standard. World J Surg 1999;23:389-96.

21. Niglio A, Grasso M, Costigliola L, et al. Laparoscopic and robot-assisted transperitoneal lateral adrenalectomy: a large clinical series from a single center. Updates Surg 2020;72:193-8.

22. Launay-Savary MV, Slim K. Evidence-based analysis of prophylactic abdominal drainage. Ann Chir 2006;131:302-5.

23. Kim EY, You YK, Kim DG, et al. Is a drain necessary routinely after laparoscopic cholecystectomy for an acutely inflamed gallbladder? A retrospective analysis of 457 cases. J Gastrointest Surg 2014;18:941-6.

24. Pędziwiatr M, Wierdak M, Ostachowski M, et al. Single center outcomes of laparoscopic transperitoneal lateral adrenalectomy--Lessons learned after 500 cases: A retrospective cohort study. Int J Surg 2015;20:88-94.

25. Villar del Moral JM, Rodríguez González JM, Moreno Llorente $\mathrm{P}$ et al. Adrenal surgery in Spain: final results of a national survey. Cir Esp 2011;89:663-9.

26. Hauch A, Al-Qurayshi Z, Kandil E. Factors associated

Cite this article as: Chai S, Pan Q, Liang C, Zhang H, Xiao X, Li B. Should surgical drainage after lateral transperitoneal laparoscopic adrenalectomy be routine?-A retrospective comparative study. Gland Surg 2021;10(6):1910-1919. doi: 10.21037/ gs-20-829 with higher risk of complications after adrenal surgery. Ann Surg Oncol 2015;22:103-10.

27. Sommerey S, Foroghi Y, Chiapponi C, et al. Laparoscopic adrenalectomy--10-year experience at a teaching hospital. Langenbecks Arch Surg 2015;400:341-7.

28. Thompson LH, Nordenström E, Almquist M, et al. Risk factors for complications after adrenalectomy: results from a comprehensive national database. Langenbecks Arch Surg 2017;402:315-22.

29. Agrama HM, Blackwood JM, Brown CS, et al. Functional longevity of intraperioneal drains: an experimental evaluation. Am J Surg 1976;132:418-21.

30. Georgiou C, Demetriou N, Pallaris T, et al. Is the routine use of drainage after elective laparoscopic cholecystectomy justified? A randomized trial. J Laparoendosc Adv Surg Tech A 2011;21:119-23.

31. Kandil TS, El Hefnawy E. Shoulder pain following laparoscopic cholecystectomy: factors affecting the incidence and severity. J Laparoendosc Adv Surg Tech A 2010;20:677-82.

32. Gurusamy KS, Samraj K, Mullerat P, et al. Routine abdominal drainage for uncomplicated laparoscopic cholecystectomy. Cochrane Database Syst Rev 2007;(4):CD006004.

33. Budd DC, Cochran RC, Fouty WJ Jr. Cholecystectomy with and without drainage. A randomized, prospective study of 300 patients. Am J Surg 1982;143:307-9.

34. Myers MB. Drain fever, a complication of drainage after cholecystectomy. Surgery 1962;52:314-7.

35. Pisarska $M$, Dworak J, Natkaniec $M$, et al. Risk factors for prolonged hospitalization in patients undergoing laparoscopic adrenalectomy. Wideochir Inne Tech Maloinwazyjne 2018;13:141-7.

36. Major P, Matłok M, Pędziwiatr M, et al. Do we really need routine drainage after laparoscopic adrenalectomy and splenectomy? Wideochir Inne Tech Maloinwazyjne 2012;7:33-9.

37. Ramírez-Plaza CP, Perales JL, Camero NM et al. Outpatient laparoscopic adrenalectomy: a new step ahead. Surg Endosc 2011;25:2570-3. 